\title{
New Practical Teaching Model Design for mutualized practical works based on low cost ICT, IOT and Al developed solutions
}

\author{
LARAKI Mehdi $^{1^{*}, \text { SEKHARA Youssef }}{ }^{1}$, GUESSOUS Soufiane ${ }^{1}$ \\ ${ }^{1}$ Study and Research Center for Engineering and Management (CERIM), School of engineering's and business' sciences and technics \\ (HESTIM), Casablanca, Morocco.
}

\begin{abstract}
Recently, Information and Communication Technology (ICT) plays a crucial role in teachinglearning, particularly tracking, trainings, knowledge management and knowledge organization. The aim of this article is to propose a new practical teaching model design for practical works based on ICT, IoT and AI Tools. This new model will allow students to acquire skills and knowledges outside their field of training related to their course. The challenge of this teaching model is to teach more practical works by adopting the learning by doing approach, with a minimum cost effect.
\end{abstract}

\section{State of the Art}

\subsection{New technologies for education}

During these last years, many teaching methods are proposed by researchers in all over the word, most of it are based on ICT solutions. In the Research works: 5 Solutions For Schools And Colleges To Modify Learning Process, the authors [1] illustrate the potential of IoT in education, where all education actors are making benefits from it.

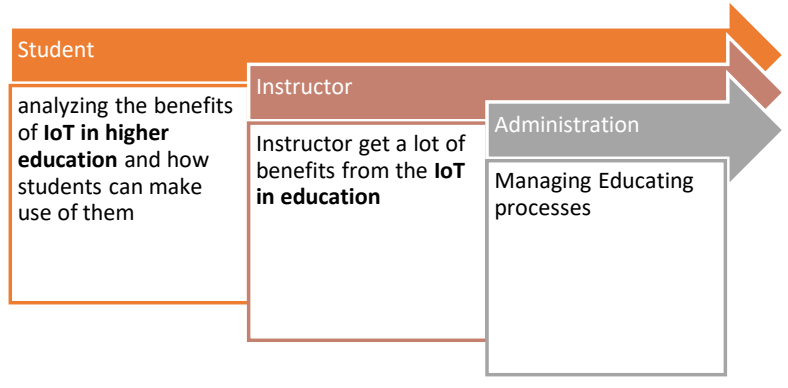

Fig. 1. Education actors

In other research works, the authors [2] present a teaching methodology for a practical course based on the virtual reality for graduate and undergraduate students. 3D visualisation virtual reality technology represents a tool that can prepare engineering students with new skills required for business. [2-7].

\subsection{Role of Practical works}

Many research works define the role of practical works in education. The term: practical work is referring to: "Any teaching and learning activity which at some point involves the students in observing or manipulating the objects and materials they are studying" [8]. In other hand, the authors illustrate the approach of developing students'scientific knowledge. Indeed, the author [9] illustrate a process of developing and implementing a practical task for an efficient practical work. The figure 3 show the links between different educational parameters, starting from objectives bloc (what students are intended to learn) until Student learning (what students actually learn).

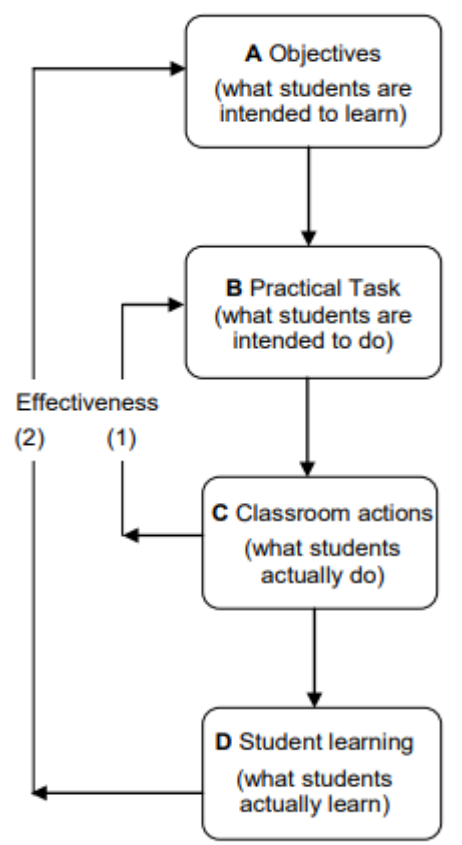

Fig. 2. The process of developing and implementing a practical task

The Practical Work allows students to analyze, discuss and find solutions to real technical problems. On the

\footnotetext{
* Corresponding author: m.laraki@hestim.ma
} 
other hand, practical work also allows students to promote the development of his practical and engineering skills.

Practical Work represents effective learning experiences. In fact, students understand not only how to experience it, but also the importance of solving the various problems linked to the practical work carried out and how it could be applied or linked to situations in the professional world.

\section{Contribution and Model Design}

\subsection{Requirement specification}

Before starting programming practical works, a study should be conducted in order to specify clearly the requirement specification for each domain. An effective practical work teaching program, is a program which take into consideration many parameters.

Our proposed Teaching Model Design for practical works present an innovative and new approach of teaching. Indeed, this teaching model will help teachers to make benefit students from all courses and practical works they did by focusing on innovative approaches:

- Making benefits students from practical works they learned.

- Awareness of multidisciplinary by pooling of a group of selected practical works in one practical work

- Awareness of the soft skills related to group working and complementarity

- $\quad$ Learning by doing

- $\quad$ Low cost practical teaching platform

- $\quad$ End to End practical works (Multidisciplinary)

The figure Fig. 3 illustrates the benefits of the new proposed model.

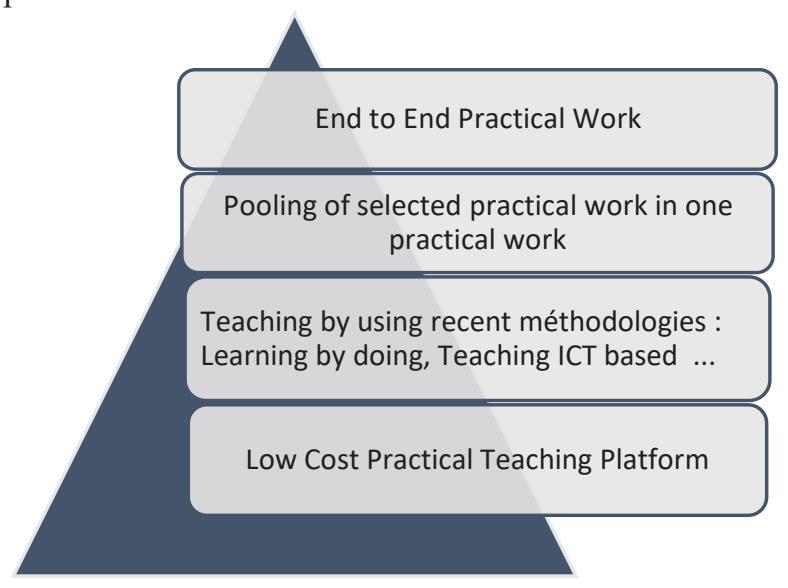

Fig. 3. New Practical Work Teaching Model

\subsection{Model Design \&Technical description}

The new practical teaching work model design is based on the most recent technologies, like IoT, AI, ICT and can be extended to new technologies as well.

Indeed, the new practical teaching work model is presented as a multi-layer model as shown in the following Fig. 4:

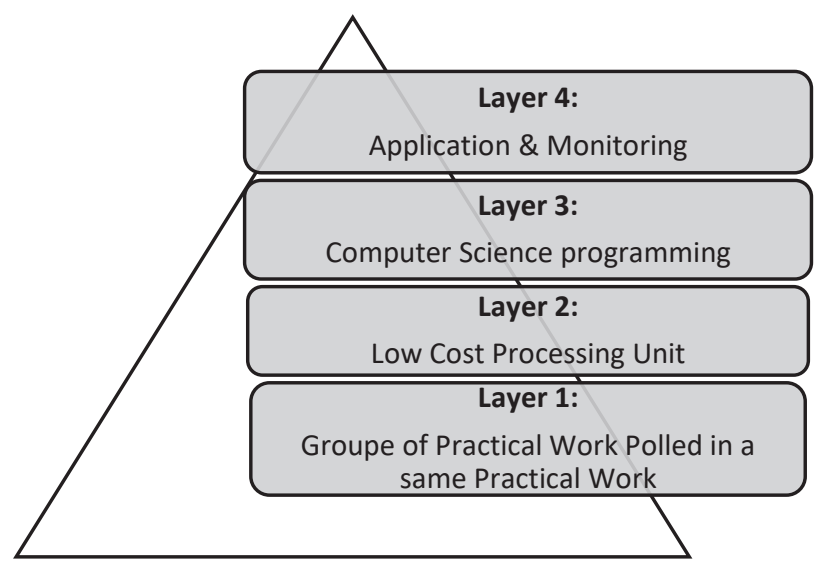

Fig. 4. Technical description of the new practical work teaching Model

Layer 1:

The layer 1 describes a list of selected practical works that teachers want to mutualize for effective and multidisciplinary practical teaching approach. We can list as an example the following list of practical works able to be mutualized:

$$
\begin{array}{ll}
\text { - } & \text { Embedded Systems practical work } \\
\text { - } & \text { Electronics practical work } \\
\text { - } & \text { Electronics practical work } \\
\text { - } & \text { Computics practical work } \\
\text { - } & \text { IoT practical work practical work } \\
\text { - } & \text { AI practical work }
\end{array}
$$

Layer 2:

We propose to design an innovative model based on a low cost processing unit system. The aim of our proposed approach is to create an effective practical work platform with less resources.

\section{Layer 3:}

The proposed platform is able to be programmed and sized in function of the pedagogical needs. Programmers will use open source software and OS (Operating System) for more efficacy and low cost.

\section{Layer 4:}

By using the proposed platform, students will be able to monitor all the practical works fulfilled. It will also allow students to develop programs and increase their computer science programing's skills while performing the objectives fixed in the Layer 1 .

\section{Model Implementation : Case of study Civil Engineering}

The objective of this chapter, is to implement our proposed model in the context of Civil Engineering. 


\subsection{Requirement specification}

First of all, we fixed a list of additional practical works that the school of the university want to mutualize. As an example, we find below a list of additional practical works Fig. 5:

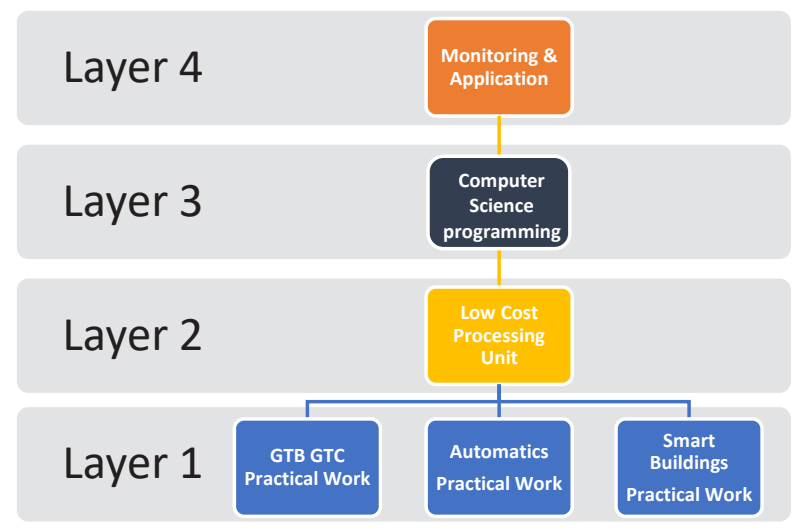

Fig. 5. Requirement specification

\subsection{Practical platform design}

In addition to a low cost Processing unit we propose to use also low cost sensors. The sensors are selected in order to create a realistic environment of "Smart Buildings" for the civil engineering students.

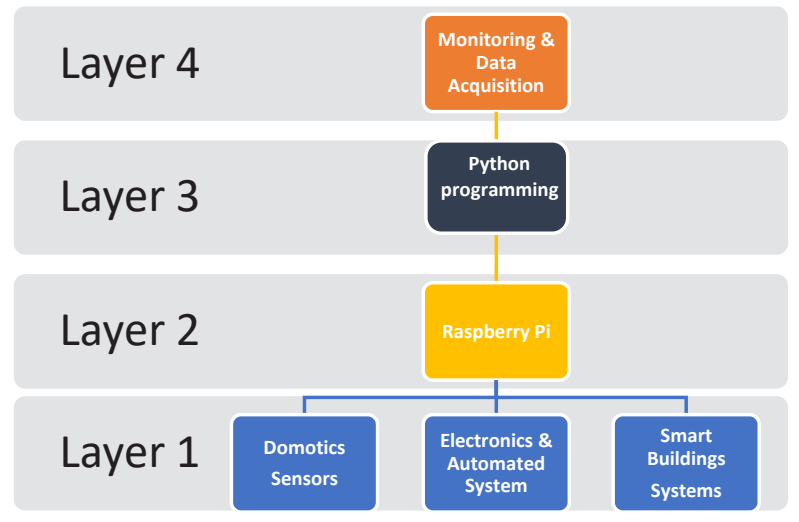

Fig. 6. Technical description of the new practical work teaching Model

\footnotetext{
A- Sensors:

- Motion detection sensors

- Temperature sensors

- Humidity sensors
}

Other sensors can be added to the platform as required

B- Electronics, Automated \& Smart Buildings System:

- Motion detection system design

- $\quad$ Temperature \& Humidity system design

- $\quad$ Signalling system design

- $\quad$ Audio System design

Other systems can be added to the platform as required

\section{C- Computer Science Programming :}

- Operating System

- Sensors programming

- Data acquisitions

- Monitoring

\subsection{Courses and practical knowledges engaged by the proposed platform}

The aim of our proposed platform is to mutualize a maximum of practical works, this mutualisation allow students increasing their practical knowledges by working on one practical work (End to End practical work).

- Electrical

- Automatics

- Electronics :

- Python programming

- Network \& Telecommunication

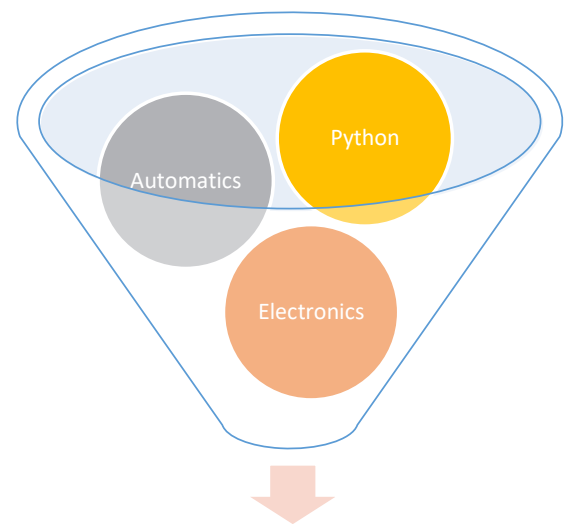

Fig. 7. Technical description of the new practical work teaching Model

\section{Model Result and discussion}

\subsection{Questionnaire}

In other to experiment our proposed Teaching Model Design, we designed a platform for teaching a course related to Domotic for Civil engineer students.

We decided to establish a questionnaires in 2 phases.

\subsection{Questionnaire's content \& Indicators}

The aim of this questionnaire is to evaluate the degree of assimilation of the civil engineering students regarding to a group of technologies presented to them in the first domotic course session. The questionnaire will also allow us to know if students are aware of the utility of the following technologies/ Knowledges: 


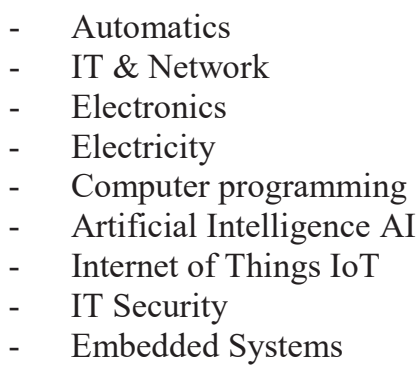

In addition. The proposed questionnaire evaluate the ability of students to link between a group of applications and the technologies presented in the domotic course session.

Finally, the questionnaire evaluate also the students' potentiality of proposing ideas of practical applications for civil engineering field.

\subsection{Questionnaire Phases}

The aim of this questionnaire Phase 1 is to evaluate student's comprehension regarding to a group of technologies presented to them during the first domotic course. Fig.8.

The aim of this questionnaire Phase 2 is to evaluate the impact of a practical session using the designed practical work platform based on the proposed practical work teaching model.

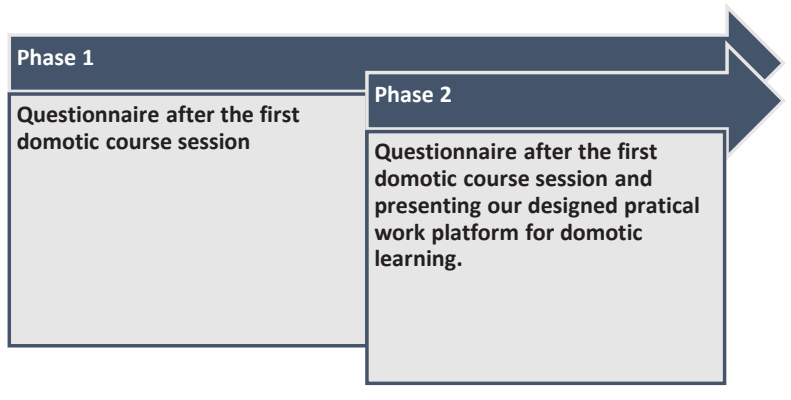

Fig. 8. Questionnaire Phases

\subsection{Educational Expectation}

The Fig. 9 illustrates the educational expectation related to the case study concerning civil engineering

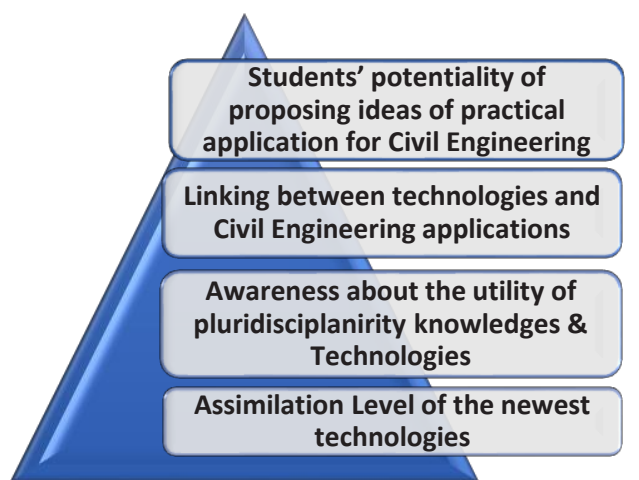

Fig. 9. Educational Expectation

\subsection{Result and discussion}

As presented in the previous chapters, a questionnaire is conducted in 2 phases. A global score is calculated for each student as the following:

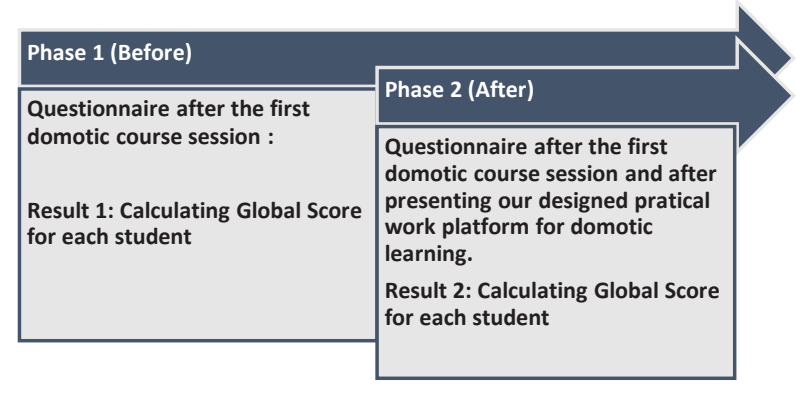

Fig. 10. Questionnaire Phases 1 \& 2 (First Course Session)

The following figure Fig.11 and Fig.12 show the result obtained after the questionnaire sessions after the first domotic course session.

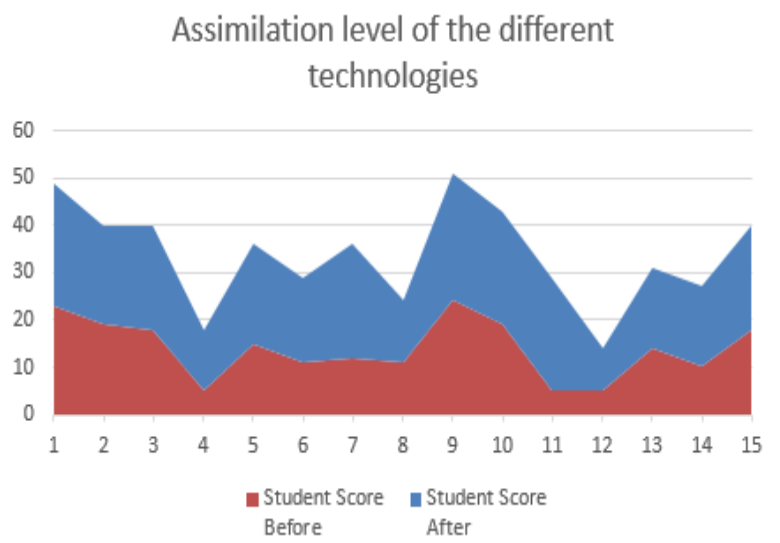

Fig. 11. Assimilation level of the different technologies

\section{Overall Pedagogical Contribution}

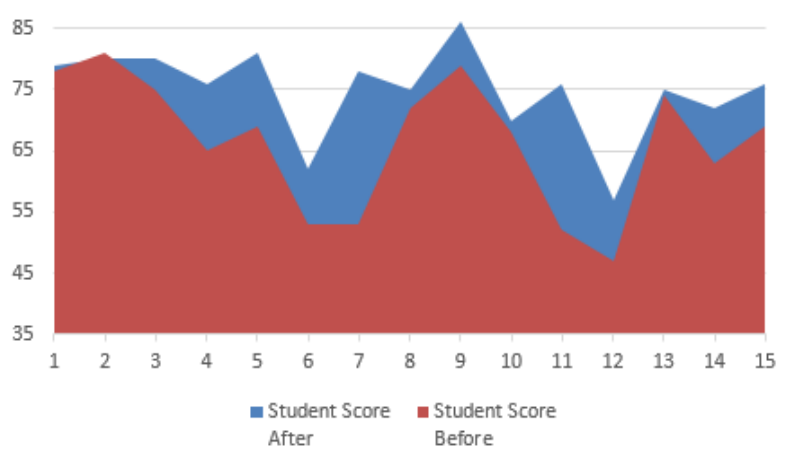

Fig. 12. Overall Pedagogical Contribution

We can notice from the results presented in Fig.11 and Fig. 12 that from the first domotic course session and by adopting the new proposed practical teaching model design for mutualized practical works, students had raised awareness and acquired skills and knowledges outside their field of training related to their course. 


\section{Conclusion \& Perspectives}

In conclusion, the new practical teaching model design for mutualized practical works allow to upgrade the student's knowledge efficiently and in a short time. Indeed teachers will be able to design efficiently their own practical works according to the educational needs and expectations. The challenge of this practical teaching model is to teach many transverse practical works in one practical work for more disciplinarity by adopting the learning by doing approach and with a minimum cost effect.

\section{References}

1. Sergey.L, IoT In Education: 5 Solutions For Schools And Colleges To Modify Learning Process, (2021), education, link: https://www.cleveroad.com/blog/iot-in-educationmain-solutions-iot-brings-to-educational-sector

2. Polina Häfner*, Victor Häfner, Jivka Ovtcharova, Teaching Methodology for Virtual Reality Practical Course in Engineering Education, Karlsruhe Institute of Technology, Zirkel 2, Karlsruhe 76185, Germany, Published by Elsevier, doi: 10.1016/j.procs.2013.11.031

3. A. G. Abulrub, A. Attridge and M. A. Williams, Virtual Reality in Engineering Education: The Future of Creative Learning, http://dx.doi.org/10.3991/ijet.v6i4.1766

4. P. Marescaa, *, E. Gómeza, J. Cajaa, C. Barajasa, R. Ledesmaa, Academic Learning Platform for Practical Classes: a learning model in Manufacturing Engineering. The Manufacturing Engineering Society International Conference, MESIC 2015, 2015 Published by Elsevier Ltd.

5. Degang Shi, Improving the practical ability of civil engineering students, World Transactions on Engineering and Technology Education, Vol.12, No.1, 2014

6. HU Xiaoqian, Zhang Lian, Li Shan, Jiang Dongrong, Practical Teaching System for Electrical Engineering Specialty Based on Engineering Ability Cultivation, International Conference on Education Technology and Information System (ICETIS 2013), Published by Atlantis Press

7. Sun Jianmin1, a, Zou Jiting1,b and Gao Linghua1, Research of Practice Teaching System for Training Civil Engineer, 3rd International Conference on Science and Social Research (ICSSR 2014).Published by Atlantis Press

8. Robin Millar, The role of practical work in the teaching and learning of science, University of York, October 2004.

9. Millar, R., Tiberghien, A. and Le Maréchal, J.F. (2002). Varieties of labwork: A way of profiling labwork tasks. In Psillos, D. and Niedderer, H. (eds.), Teaching and Learning in the Science Laboratory (pp. 9-20). Dordrecht: Kluwer Academic 